КАБЕЛИ И ПАССИВНОЕ

ОБОРУДОВАНИЕ

\title{
В НАЧАЛЕ СЛАВНЫХ ДЕЛ: \\ ОПТИЧЕСКОМУ ОТДЕЛУ \\ ВНИИКП - 40 ЛЕТ
}

С.Попов

DOI: $10.22184 / 2070-8963.2019 .84 .7 .34 .39$

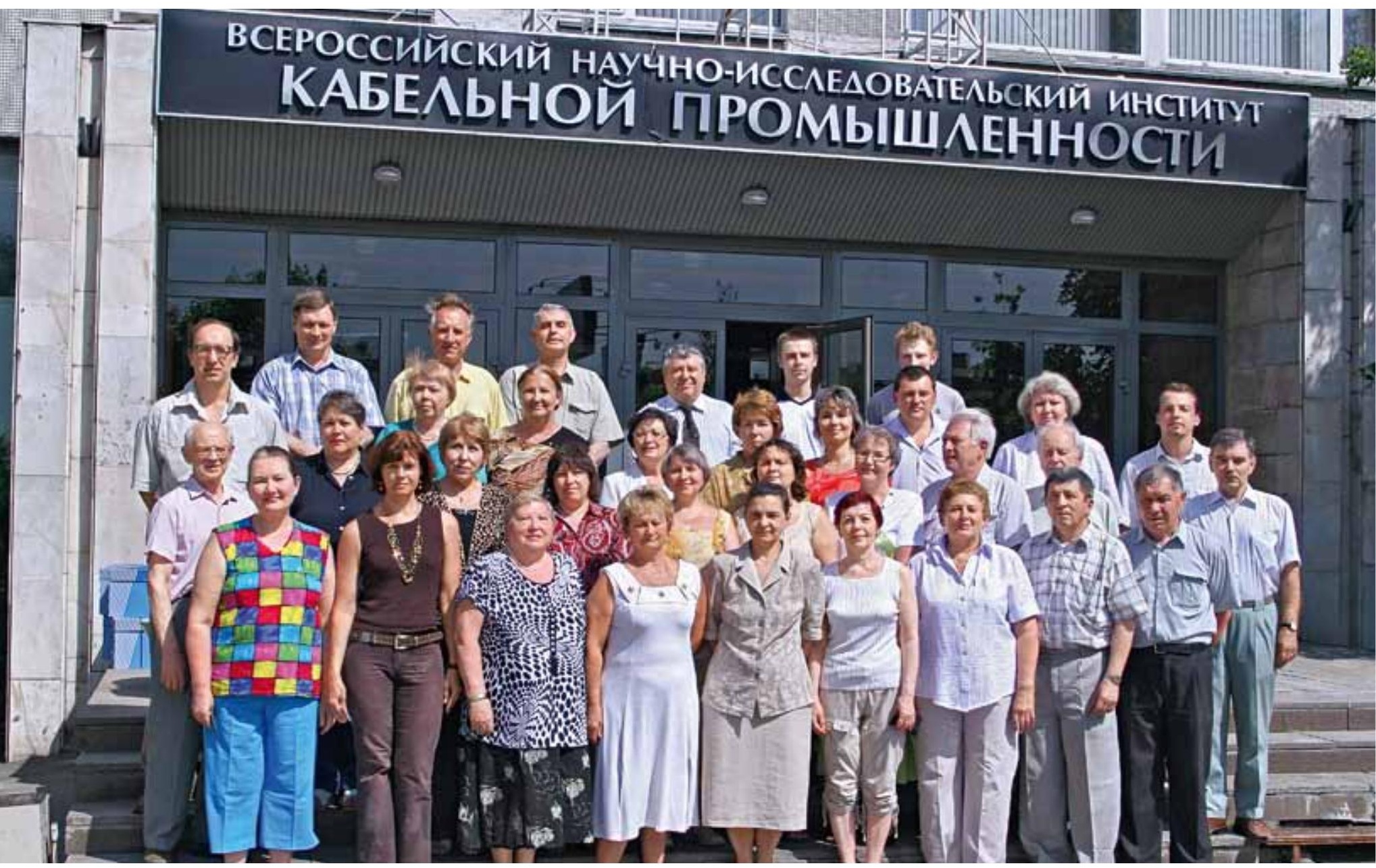

Осенью 1979 года во Всесоюзном НИИ кабельной промышленности (ныне - ОАО "ВНИИКП") был создан новый отдел № 11 - оптических кабелей. С тех пор и по сей день ученые и специалисты института осуществляют научное сопровождение и разработки в сфере одного из наиболее успешных направлений российских телекоммуникаций - производства оптических кабелей и волокна. 
Сегодня вряд ли нужно кого-то убеждать, что оптические кабели (OK) - фундамент современных телекоммуникационных сетей, включая сотовые любых поколений, и объектовых систем связи. В 1970-е же в перспективности новых технологий сомневались многие. Но только не специалисты ВНИИКП, которые поставили себе задачу в стране, где и традиционные медножильные кабели связи были в хроническом дефиците, с нуля разработать конструкции ОК, технологии их изготовления и организовать промышленное производство инновационной продукции. Переход электросвязи на "оптику" начинался в стенах института на шоссе Энтузиастов.

Волоконной оптикой во ВНИИКП начали заниматься еще в 1976 году, когда в отделе кабелей связи была создана волоконно-оптическая лаборатория. Вскоре ее сотрудники Г.И.Пронин и А.А.Семенов на оборудовании Опытного завода (О3) ВНИИКП изготовили первые образцы отечественного ОК. А уже в 1977 году кабель, созданный во ВНИИКП на основе оптического волокна (ОВ), произведенного в ГОИ им. С.И.Вавилова, был продемонстрирован на 2-й Международной выставке "Связь" в составе действующей линии для передачи сигналов цветного ТВ.

В 1979 году в институте был организован отдел оптических кабелей, включивший четыре лаборатории (магистральных ОK, специальных OK, оптического волокна (ОВ) и заготовок, измерительная) и опытный технологический участок. Возглавил отдел Ю.Т.Ларин. Вопросами ОВ занималась лаборатория под руководством С.Э.Питерских. Ведущими специалистами отдела в годы становления были Э.Я.Геча, Л.З.Зеликсон, В.И.Метальников, С.М.Новохатко, Л.Г.Рысин, Ю.В.Смирнов, Ю.Г.Шахназаров, Г.А.Черенков. Некоторые из тех, кто принимал участие в первых шагах "оптики", работают во ВНИиКП и сегодня - Н.В.Галкина, А.А.Семенов, Н.Д.Шкалова.

На ОЗ ВНИИКП в 1982-1983 годах впервые в стране было налажено промышленное производство телекоммуникационного ОВ по лицензии и на оборудовании французской компании "Кварц и Силис". В последующие годы на заводе осуществлялся выпуск ОВ типа "кварц-полимер" (с диаметром по кварцевой сердцевине от 200 до 1000 мкм) в объеме до 3 тыс. км в год. Использовалась длина волны 0,85 мкм. Тогда же было осуществлено строительство корпуса для производства OK на московском заводе "Электропровод". Сегодня этот завод успешно продолжает работать в Подольске на вновь построенных площадях.

В дальнейшем, в связи с введением западными странами эмбарго на экспорт в СССР продукции двойного назначения, для изготовления заготовок

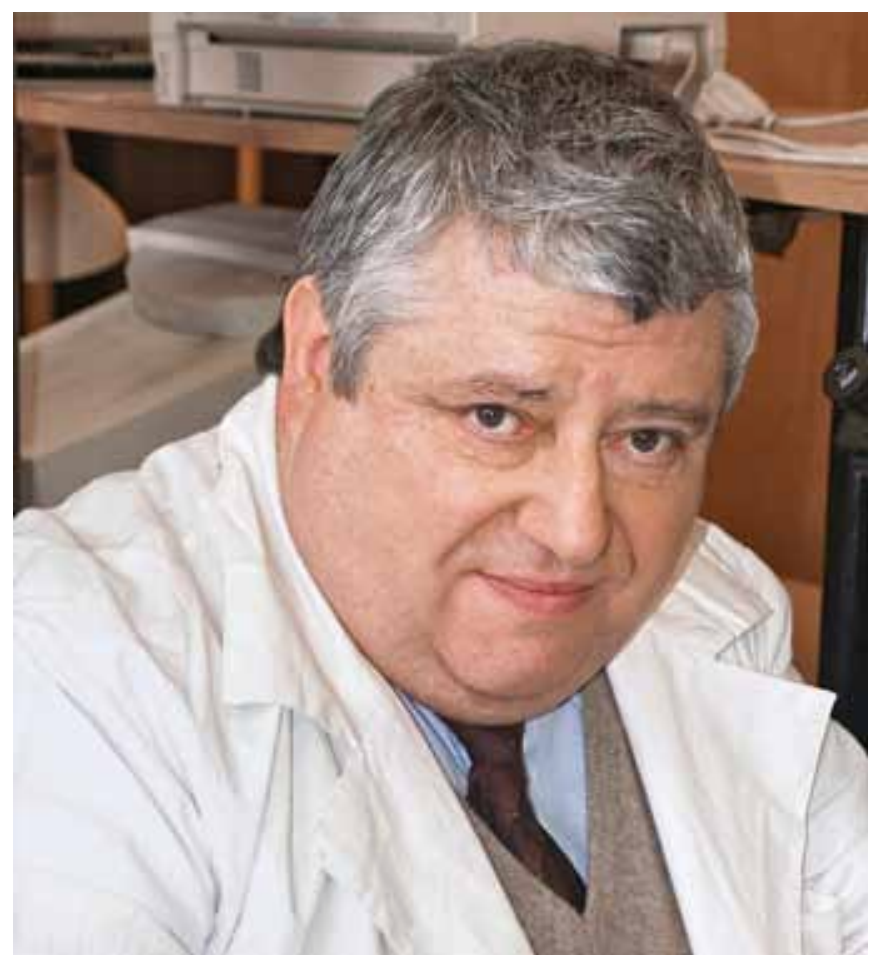

Ю.Т.Ларин - первый начальник отдела оптических кабелей

(преформ) и вытяжки ОВ использовалось оборудование в основном отечественного производства. Практически весь парк измерительной техники для волоконно-оптической связи и аппаратов для сварки волокна также базировался на отечествен ${ }^{-}$ ных разработках.

В 1981-1985 годах отделом оптических кабелей были разработаны первые: полевые OK; магистральные, внутризоновые и городские OK с затуханием менее 3 дБ/км на длине волны 1,3 мкм; оптические кабели с продольной и поперечной герметизацией для объектов ВМФ; монтажные ОК и др. Многие разработанные во ВНИИКП типовые конструкции ОК актуальны до сих пор.

ВНИИКП был головным предприятием Межотраслевого научно-технического комплекса (МНТК) "Световод", организованного постановлением ЦК КПСС и Совмина СССР "для создания и серийного производства оптических волокон и кабелей с характеристиками, соответствующими мировому техническому уровню или превышающими его, а также разработки и внедрения передовой промышленной технологии и высокоэффективного оборудования для их производства". В состав комплекса вошло свыше 20 научных и производственных предприятий.

За время до распада СССР удалось не только решить многие научные задачи волоконной оптики, но 


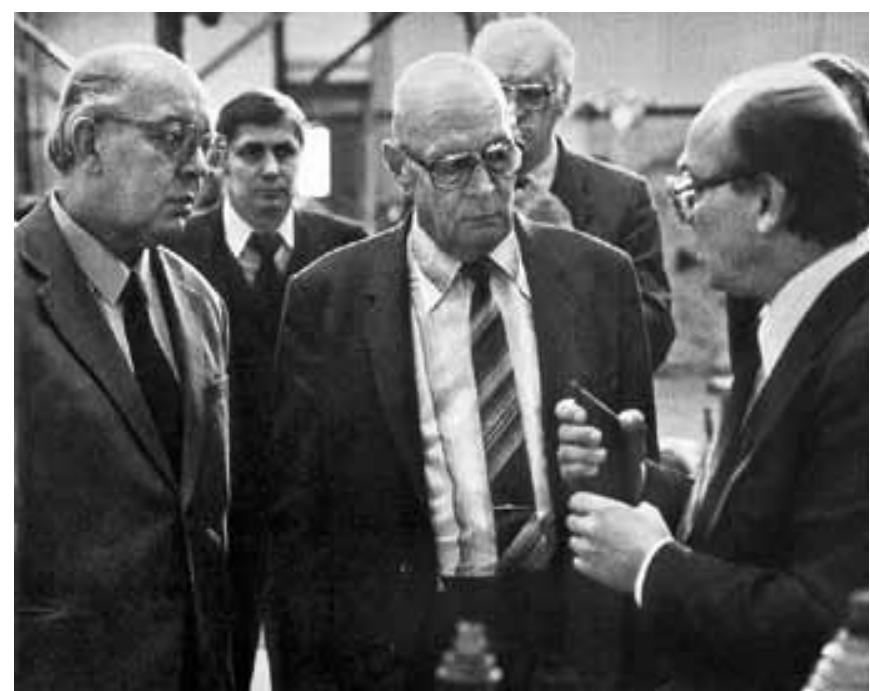

И.Б.Пешков обсуждает планы развития производства ОК с президентом АН СССР А.П.Александровым

и наладить выпуск ОK на пяти кабельных заводах. Сегодня таких заводов в РФ и СНГ - 19.

Однако после введения рыночных отношений производство ОВ в первый же год упало на $60 \%$, а вскоре было закрыто на всех заводах кроме "Электропровода". В страну стали завозиться волокна и кабель иностранного производства, которые были дешевле и отличались лучшим качеством. При этом отечественное производство ОК развивалось, хотя и на базе импортных оптических волокон и других материалов.

И все-таки вытяжка телекоммуникационного ОВ в России была налажена, во что немалый вклад внесли в том числе специалисты ВНИИКП. В мае 2015 года в Саранске на заводе "Оптиковолоконные Системы" (OBC) была изготовлена первая партия российского одномодового волокна типа G.652.D.

B последние десятилетия ВНИИКП концентрируется на создании ОК специального назначения. Под руководством Ю.Т.Ларина были разработаны оптические полевые кабели ОК-ПН, уже свыше 15 лет применяемые в различных системах связи военного назначения, в том числе в составе армированных кабелей П-294, а также судовые ОК, в том числе обладающие продольной герметичностью при повышенном гидростатическом давлении.

В 1999-2005 годах проведена уникальная НИОКР по созданию основных компонентов сматываемых волоконно-оптических линий передачи информации систем управления и наведения объектов, работающих в условиях воздействия гидростатического давления до 10 МПа, в результате которой разработаны миниатюрный ОК диаметром 900 мкм со

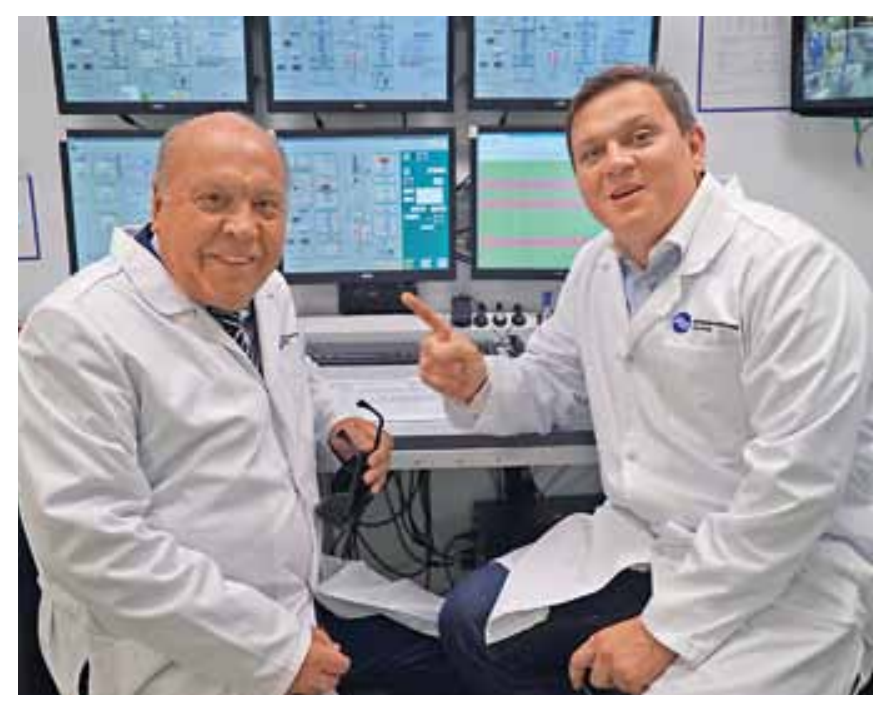

Генеральные директоры ОАО "ВНИИКП" Г.И.Мещанов (слева) и АО "Оптиковолоконные Системы" А.В.Николаев в цеху ОВС

строительной длиной 50 км, оптический кабель-трос и безынерционные катушки, обеспечивающие размотку кабелей со скоростью до $30 \mathrm{M} / \mathrm{c}$, электрооптические кабели для аэромобильных комплексов и др. Основной научный вклад в эти разработки внесли Э.Я.Геча, Ю.Т.Ларин, И.А.Овчинникова. В работе участвовали и совсем молодые кабельщики, в те годы еще студенты МЭИ М.В.Дуйнов и И.Г.Калюжная, теперь руководители АО "Электропровод".

В последние годы особое внимание уделялось пожаробезопасности ОК. В 2010 году разработан и включен в Перечень изделий, разрешенных к применению в военной технике, судовой оптический комбинированный кабель специального назначения с четырьмя медными жилами, не распространяющий горения при вертикальной групповой прокладке.

С 2011 по 2014 год под руководством Е.Б.Васильева и И.А.Овчинниковой для удовлетворения потребности предприятий атомной промышленности были разработаны и освоены в производстве первые отечественные оптические кабели для систем 2 и 3 класса безопасности АЭС. Эти ОК являются сейсмостойкими, не распространяют горение при групповой прокладке (категория A), не имеют в своем составе галогенсодержащих и коррозионно-активных материалов, сохраняют работоспособность в условиях воздействия пламени в течение 60 мин.

Все время деятельности отдела велась разработка различных методов испытаний и нормативной документации, в том числе национальных и военных стандартов. За последнее десятилетие разработано более 30 различных стандартов в области ОК и ОВ. 
Сотрудниками было получено более 100 патентов на изобретения и полезные модели, опубликовано свыше 500 статей и тезисов научных докладов.

Журнал обратился к нескольким непосредственным участникам процесса организации российского производства ОВ и ОК с просьбой поделиться воспоминаниями.

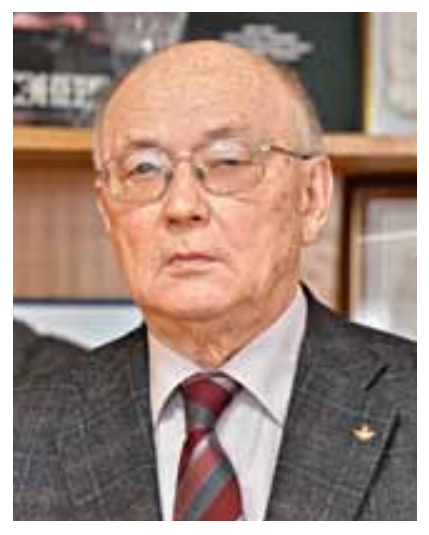

И.Б.Пешков, д.т.н. председатель Совета директоров ОАО "ВНИИКП"

Как осуществлялась координация создания волоконно-оптической техники?

ВНИИКП начал деятельность в области оптических кабелей во второй половине 70-х годов. Была создана специализированная лаборатория, которая позволила подготовить комплексные работы в этом научном направлении.

Важнейшее решение о проведении необходимых работ было принято сверху, когда был создан МНТК "Световод". В 1987 году для активизации работы в МНТК были привлечены новые силы: научным руководителем стал нобелевский лауреат академик А.М.Прохоров, а генеральным директором МНTК назначили меня. Несколько позднее заместителями гендиректора МНTК был назначены первый заместитель генерального директора НПО ВНИИКП Г.И.Мещанов и будущий академик (а в то время членкорреспондент АН СССР) Е.М.Дианов - заместитель А.М.Прохорова. Таким образом, во главе процесса создания новой техники стояли Академия наук и наш институт, бывший в те годы достаточно большой организацией, в состав которой входили и некоторые кабельные заводы.

Главной трудностью было то, что потенциальные потребители оптических кабелей, в первую очередь связисты-эксплуатационники, вовсе не горели желанием переходить на "оптику". Медные кабели стоили дешевле и вполне их устраивали. И кабельные заводы не очень хотели осваивать новую продукцию, так как медные кабели у них шли нарасхват, их не хватало. В этих условиях нам пришлось совместно с руководством Минсвязи СССР вести большую разъяснительную работу, проводить много совещаний. Постепенно было налажено производство оптических кабелей на пяти заводах: ОЗ ВНИИКП, ОКБ КП, "Электропровод", "Одесскабель" и "Севкабель", хотя поначалу и приходилось им "забивать" в план эту сложную продукцию.

К сожалению, к моменту распада СССР мы не успели наладить промышленного производства оптического волокна телекоммуникационного назначения, а затем на разработку и организацию производства уже не было средств. Спустя многие годы вытяжка волокна организована в Саранске компанией "ОВС". Но стране необходимо иметь и собственное производство преформ, которые используются для вытяжки, - иначе мы не застрахованы от форс-мажора в случае проблем с поставкой преформ по импорту.

За счет чего российской кабельной промышленности удалось сохранить за собой подавляющую долю отечественного рынка оптических кабелей?

Поодиночке каждому предприятию выстоять было бы трудно. Большую роль сыграло то, что группе инициативных директоров во главе с руководством ВНИИКП удалось в новых рыночных условиях без какой-либо господдержки сохранить единство кабельных предприятий, которые в своем большинстве объединены в Ассоциацию "Электрокабель". Сегодня заводы - члены Ассоциации, производят около 3/4 всей российской кабельной продукции. Ассоциация "Электрокабель" дважды в год проводит свои двухдневные общие собрания, на которых обсуждается все, что волнует заводы, вырабатывается совместная позиция.

Быть конкурентными на рынке нашим заводам позволяет и то, что мы сохранили единый научный центр отрасли - ВНИИКП. Он имеет не только достаточное количество специалистов высокой квалификации, но и обеспечивает стандартизацию, сертификацию, вместе с Ассоциацией "Электрокабель" активно участвует в борьбе за качество продукции, в общероссийской борьбе с фальсификатом.

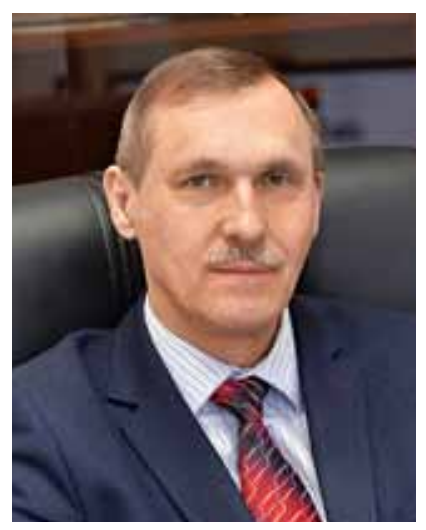

С.Л.Семенов, д.ф.-м.н. директор Научного центра волоконной оптики Российской академии наук

Какие формы сотрудничества были у НЦВО РАН с Институтом кабельной промышленности за последние 40 лет (с момента образования отдела оптических кабелей во ВНИИКП)?

В основном сотрудничество осуществля лось через МНТК "Световод". Также регулярно проходили рабочие встречи сотрудников для 
обсуждения вопросов, связанных с волоконной оптикой. Особенно активное общение происходило на уровне руководства (нашего руководителя Евгения Михайловича Дианова с руководством ВНИИКП) - с целью проведения согласованных действий в Правительстве и ведомствах по продвижению волоконной оптики в СССР и, затем, в Российской Федерации.

Какое участие приняли ученые НЦВО РАН, преемника отдела волоконной оптики Института общей физики, в организации первого в современной России промышленного производства телекоммуникационного ОВ?

Ученые НЦВО РАН принимали активное участие в организации производства оптического волокна в г. Саранске. Для одобрения в РОСНАНО проект должен был, в частности, содержать обширное описание инновационных технологий и продукции (обязательно с наносоставляющей). Эту часть проекта писали мы.

Продолжается ли сотрудничество НЦВО РАН с российской кабельной промышленностью и в том числе с ОАО "ВНИИКП"?

Да, конечно. В частности, мы участвуем в решении технических и технологических проблем, возникающих при тестировании оптического волокна российского производства, проводимом для его сертификации и паспортизации.

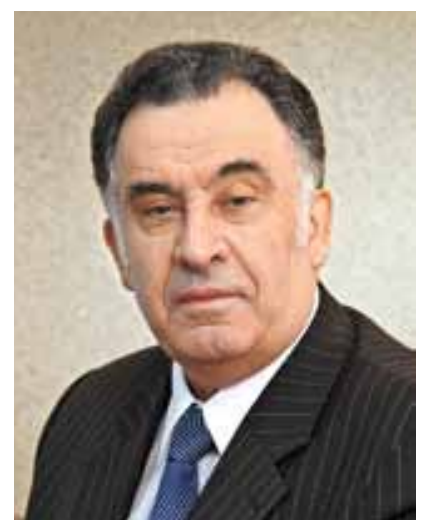

Э.А.Боксимер, почетный доктор электротехники председатель Совета директоров Группы компаний "Оптикэнерго"

Как развивалось оптическое направление в холдинге "Оптикэнерго"?

Корни развития этого направления уходят в 1996 год, когда было

принято решение об организации в Саранске производства OK. Поистине неоценимый вклад в его налаживание внесли И.Б.Пешков, в то время генеральный директор ВНИИКП; Г.И.Мещанов, ныне - руководитель института, Ю.Т.Ларин, руководитель научного направления. На всех этапах становления они шли рука об руку с заводчанами. Нам в ту пору не хватало опыта в новом для нас деле, и помощь института была как никогда кстати. Был дефицит оптического волокна. И с этой проблемой ВНИиКП нас не оставил наедине. Отдельной благодарности за это заслуживает ТД ВНИИКП в лице генерального директора Е.Б.Васильева и его первого заместителя В.И.Николаева.

В ГК "Оптикэнерго" производством ОК занимается ООО "Сарансккабель-Оптика", которому в будущем году исполняется 20 лет. В первый год существования завод производил не более 50-100 км в месяц. В 2006 году с вводом в строй второго цеха был дан старт уникальному для России проекту - производству ОК, встроенного в грозозащитный трос. Мы стали первыми в стране, кто освоил этот высокотехнологичный и востребован ный продукт. И в развитии этого проекта принимали активное участие сотрудники ВНИИКП. За 13 лет российским энергетикам поставлено свыше 50 тыс. км оптического грозотроса и полностью замещен импорт аналогичных изделий.

2012 год ознаменовался запуском третьего цеха, в котором было налажено производство внутриобъектового кабеля для широкополосного доступа по технологии "волокно в дом".

В 2019 году введен в эксплуатацию новый цех завода "Сарансккабель-Оптика", вобравший в себя все самые передовые технологии и оборудование. Это и еще один комплекс полного цикла для производства ОК, и линии по изготовлению LAN-кабеля.

За все время своей деятельности ООО "Сарансккабель-Оптика" переработало более 5 млн км ОВ и продолжает наращивать объемы производства.

\section{Как идет сотрудничество ГК "Оптикэнерго" и ОАО "ВНИИКП"?}

Все эти годы мы сотрудничали и продолжаем сотрудничать с ВНИИКП. Институт оказывает научную, методическую и консультационную помощь в разработке и постановке на производство различных видов кабельных изделий. Специалисты ВНИИКП на постоянной основе информируют нас о новинках на рынке материалов для изготовления кабелей и проводов и осуществляют их поставки в наш адрес. Регулярно проводятся деловые встречи и совместные совещания.

Сотрудники института - желанные гости на заводе. Очень часто бывал у нас и Ю.Т.Ларин, добрую память о котором мы сохраним в наших сердцах. Среди постоянных гостей завода-директор научного направления И.А.Овчинникова, заведующий отделом Д.А.Тарасов. 
В настоящее время ведется совместная работа по многим направлениям, в том числе по созданию ГОСТа на оптические кабели, готовятся к постановке на производство OK: полевые, акусточувствительные, для нужд Министерства обороны РФ.

Коллектив ГК "Оптикэнерго" поздравляет всех сотрудников ОАО "ВНИИКП" с 40-летием с момента создания научного направления по разработке оптических волокон и кабелей, благодарит за помощь и поддержку, желает крепкого здоровья и успехов в труде! Мы уверены, что наше сотрудничество будет продолжаться долгие годы и принесет много пользы не только нашим компаниям, но и кабельной отрасли в целом!

Отдел-юбиляр сегодня является составной частью отделения "Кабели, провода и арматура для систем телекоммуникаций и информатизации". Мы попросили заведующую отделением И.А.Овчинникову рассказать о сегодняшних направлениях разработок.

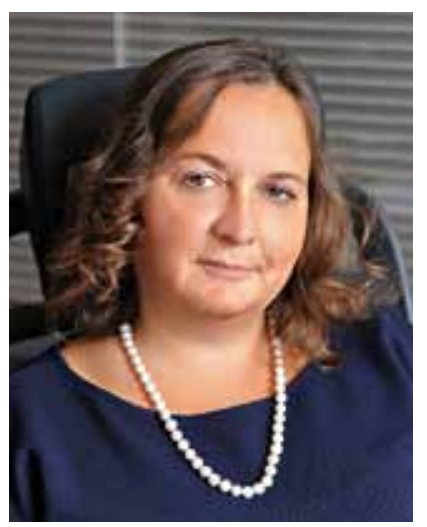

И.А.Овчинникова, к.т.н. директор научного направления - заведующая отделением "Кабели, провода и арматура для систем телекоммуникаций и информатизации" ОАО "ВНИИКП"

Самым большим нашим достижением, после разработки пожаробезопасных огнестойких OK 2 и 3 класса безопасности, считаю завершающуюся сейчас работу по созданию технологий производства преформ и вытяжки радиационностойкого одномодового ОВ, не уступающего по характеристикам импортным аналогам и способного работать на двух длинах волн - 1,31 и 1,55 мкм - в диапазоне от -60 до $100^{\circ} \mathrm{C}$. На основе данного волокна разработаны и освоены в производстве радиационно-стойкие кабели, ориенти рованные на эксплуатацию на объектах космической техники. Отмечу, что эти кабели более чем на $80 \%$ производятся из отечественных материалов.

Одной из важнейших задач, которую отделение старается решить в настоящий момент, является систематизация и стандартизация требований, предъявляемых к оптическим кабелям (OK). Мы должны оградить рынок от некачественной продукции, которая создает нечестную ценовую конкуренцию, что является одной из причин недозагрузки отечественных заводов. К сожалению, цена является сегодня главным параметром ОК для ряда потребителей, что может привести к печальным последствиям для работоспособности линии связи. При отсутствии стандартизованных методов контроля потребитель не может быть уверен в качестве приобретаемого кабеля, а добросовестные производители, честно испытывающие свою продукцию, зачастую проигрывают на рынке тем, кто "гарантирует соответствие требованиям" применяемыми материалами или просто внешним видом. Сегодня мы ведем разработку, можно сказать, главного стандарта на OK: ГОСТ Р "Кабели оптические. ОТУ", в котором должны быть систематизированы требования к условным обозначениям, основным параметрам и методам контроля телекоммуникационных OK.

Много внимания мы уделяем работе по поиску отечественных материалов для ОК, проводим их апробацию и испытания в составе кабелей, участвуем, при необходимости, в доработке, а в некоторых случаях осуществляем руководство разработкой новых материалов. Считаем своим долгом поддержку отечественных производителей кабельных материалов, в частности, первого производства ОВ в Саранске. Проводим испытания его продукции, ищем пути расширения области ее применения, например, в специальных OK, оптических кабелях-датчиках и др. Ведется подготовительная работа и по созданию производства многомодовых OB, которые пока на 100\% импортируются.

Важное направление нашей работы - испытания ОК любого назначения по методикам, приведенным в международных и отечественных стандартах, а также по методикам собственной разработки. Для контроля качества кабелей и материалов кабельного производства во ВНИИКП создан испытательный центр, богатая техническая база которого позволяет решать такие задачи, как подтверждение соответствия требованиям нормативной документации, комплексная оценка пожарной безопасности кабельной продукции, оценка надежности, диагностирование остаточного срока службы ОК, находящихся в эксплуатации, определение стойкости к внешним воздействующим факторам. Центр имеет широкую область аккредитации и аттестован как в Росаккредитации, так и в Росатоме, Интергазсерте и Морском регистре судоходства.

Редакция "ПЕРВОЙ МИЛИ" поздравляет кабель щиков-оптиков с юбилейной датой! Так держать! 